\title{
América Latina e o giro decolonial
}

\author{
Decolonial turn and Latin America
}

Hasta que los leones tengan sus propios historiadores, las historias de cacería seguirán glorificando al cazador.

Provérbio africano

O objetivo principal deste artigo é o de apresentar a constituição, a trajetória e o pensamento do Grupo Modernidade/Colonialidade (M/C), constituído no final dos anos 1990. Formado por intelectuais latino-americanos situados em diversas universidades das Américas, o coletivo realizou um movimento epistemológico fundamental para a renovação crítica e utópica das ciências sociais na América Latina no século XXI: a radicalização do argumento pós-colonial no continente por meio da noção de "giro decolonial". Assumindo uma miríade ampla de influências teóricas, o M/C atualiza a tradição crítica de pensamento latino-americano, oferece releituras históricas e problematiza velhas e novas questões para o continente. Defende a "opção decolonial" - epistêmica, teórica e política - para compreender e atuar no mundo, marcado pela permanência da colonialidade global nos diferentes níveis da vida pessoal e coletiva.

O trabalho está estruturado em duas partes. Em um primeiro momento é traçada uma breve genealogia do pós-colonialismo, propondo pensá-lo de um modo mais abrangente. O pós-colonialismo no contexto do argumento

\footnotetext{
É professora do Programa de Pós-Graduação em Ciência Política da Universidade Federal de Pelotas (Pelotas, RS). E-mail: luballestra@gmail.com.
} 
deste artigo aparece como precursor para o desenvolvimento do argumento pós-colonial que é radicalizado pelo M/C. Posteriormente, apresenta-se a constituição do grupo, a partir de seu rompimento com os estudos subalternos latino-americanos, bem como alguns conceitos centrais criados e compartilhados pelos seus principais expoentes. Ao introduzir essa discussão, o artigo sugere que a identificação e a superação da colonialidade do poder, do saber e do ser, apresenta-se como um problema desafiador a ser considerado pela ciência e teoria política estudada no Brasil.

\section{Uma breve genealogia do pós-colonialismo}

Depreendem-se do termo "pós-colonialismo" basicamente dois entendimentos. O primeiro diz respeito ao tempo histórico posterior aos processos de descolonização do chamado "terceiro mundo", a partir da metade do século XX. Temporalmente, tal ideia refere-se, portanto, à independência, libertação e emancipação das sociedades exploradas pelo imperialismo e neocolonialismo - especialmente nos continentes asiático e africano. A outra utilização do termo se refere a um conjunto de contribuições teóricas oriundas principalmente dos estudos literários e culturais, que a partir dos anos 1980 ganharam evidência em algumas universidades dos Estados Unidos e da Inglaterra.

Como tantas escolas orientadas pelo "pós", o pós-colonialismo se tornou uma espécie de "moda" acadêmica, tendo penetrado tardiamente nas ciências sociais brasileiras. Costa afirmou que o pós-colonialismo compartilha, em meio suas diferentes perspectivas, do "caráter discursivo do social", do "descentramento das narrativas e dos sujeitos contemporâneos", do "método da desconstrução dos essencialismos" e da "proposta de uma epistemologia crítica às concepções dominantes de modernidade" (Costa, 2006, p. 83-84). $\mathrm{Na}$ continuidade do argumento, sugere ainda que o "colonial" do termo "alude a situações de opressão diversas, definidas a partir de fronteiras de gênero, étnicas ou raciais”. Sobre esse ponto, nota-se que nem todas as situações de opressão são consequências do colonialismo - veja-se a história do patriarcado e da escravidão -, ainda que possam ser reforçadas ou ser indiretamente reproduzidas por ele. Em suma, ainda que não haja colonialismo sem exploração ou opressão, o inverso nem sempre é verdadeiro.

$\mathrm{Na}$ primeira chave de interpretação, o autor perceptivelmente associa o pós-colonialismo com as condições de emergência oferecidas pelos estudos pós-estruturais, desconstrutivistas e pós-modernos. De fato, ela se aplica a 
vários autores diaspóricos citados no livro Dois Atlânticos, mas apaga duas noções importantes. A primeira é o fato de pensadores pós-coloniais poderem ser encontrados antes mesmo da institucionalização do pós-colonialismo como corrente ou escola de pensamento. A segunda é o fato de que o pós-colonialismo surgiu a partir da identificação de uma relação antagônica por excelência, ou seja, a do colonizado e a do colonizador. Se por um lado essa fixação binária de identidades essencializadas foi rompida nos escritos de $\mathrm{Memmi}^{1}$, Said, Spivak e Bhabha, por outro, ela foi permitida pela identificação daquilo que Mignolo (2003) chamou de "diferença colonial". Nesse sentido, a relação colonial é uma relação antagônica: “[A] presença do outro me impede de ser totalmente eu mesmo. A relação não surge de identidades plenas, mas da impossibilidade da constituição das mesmas" (Laclau e Mouffe, 1985, p. 125). Foi Fanon (2010) quem pela primeira vez expressou esse impedimento, em 1961.

Franz Fanon soma-se a um conjunto de autores precursores do argumento pós-colonial, cujas primeiras elaborações podem ser observadas pelo menos desde o século XIX na América Latina². Nesse período, a América Latina atravessou "o seu" período pós-colonial, com reprodução daquilo que Casanova (2002) chamou de "colonialismo interno". Por sua vez, expressões anticoloniais puderam também ser encontradas em pensadores europeus, europeístas e eurocêntricos (Merle e Mesa, 1972).

Mesmo que não linear, disciplinado e articulado, o argumento pós-colonial em toda sua amplitude histórica, temporal, geográfica e disciplinar percebeu a diferença colonial e intercedeu pelo colonizado. Em essência, foi e é um argumento comprometido com a superação das relações de colonização, colonialismo e colonialidade. Dessa forma, ele não é prerrogativa de autores diaspóricos ou colonizados das universidades periféricas. Essa ponderação se faz importante, visto que, para certa crítica ao pós-colonialismo (Feres Jr. e Pogrebinschi, 2010), isso determinaria a legitimidade de quem com ele trabalha.

\footnotetext{
"A vida nos tratou de maneira diferente; ele (o francês nascido na África do Norte) era reconhecido como filho legítimo da metrópole, herdeiro do privilégio, que ele defenderia a qualquer preço, até mesmo o mais escandaloso; eu era uma espécie de mestiço da colonização, que compreendia a todos porque não pertencia totalmente a ninguém" (Memmi, 2007).

Do ensaísmo literário ao marxismo latino-americano, passando pela teoria da dependência à filosofia da libertação, nota-se que o problema da colonialidade esteve fortemente presente no pensamento político latino-americano. No século XIX, escritores, políticos e ativistas (Bolívar, Bilbao, Torres-Caicedo, Martí, Rodó e Bonfim, para citar alguns) destinaram suas preocupações ao "sentido" e o "destino" da América e de seus povos mediante o problema da colonização ibérica. Para a ideia "latinidade" como uma estratégia imperial francesa adotada pelas elites criollas do continente na segunda metade do século XIX, ver Mignolo (2007b).
} 
Aquilo que é considerado clássico na literatura pós-colonial é passível de questionamento, como a eleição dos próprios clássicos das ciências sociais (Connel, 2007). Porém, existe um entendimento compartilhado sobre a importância, atualidade e precipitação da chamada "tríade francesa", Césaire, Memmi e Fanon, talvez pelo fato de o argumento pós-colonial ter sido, pela primeira vez, desenvolvido de forma mais ou menos simultânea. Franz Fanon (1925-1961) - psicanalista, negro, nascido na Martinica e revolucionário do processo de libertação nacional da Argélia -, Aimé Césaire (1913-2008) - poeta, negro, também nascido na Martinica - e Albert Memmi (1920) - escritor e professor, nascido na Tunísia, de origem judaica - foram os porta-vozes que intercederam pelo colonizado quando este não tinha voz, para usar os termos de Spivak. Os livros Retrato do colonizado precedido de retrato do colonizador (1947), de Albert Memmi, Discurso sobre o colonialismo (1950), de Césaire, e Os condenados da terra (1961), de Franz Fanon, foram escritos seminais. Os dois últimos foram agraciados com prefácios de Jean-Paul Sartre, que em um "complexo de culpa" europeia, recomenda suas leituras, elogia seus autores e, logo, intercede pelos colonizados. A esses três clássicos soma-se a obra Orientalismo (1978), de Edward Said (1935-2003), crítico literário de origem palestina, intelectual e militante da causa. O Oriente como "invenção" do Ocidente denunciou a funcionalidade da produção do conhecimento no exercício de dominação sobre o "outro". Estes quatro autores contribuíram para uma transformação lenta e não intencionada na própria base epistemológica das ciências sociais.

De forma paralela, é indispensável apresentar outro movimento que acabou por reforçar o pós-colonialismo como um movimento epistêmico, intelectual e político. Na década de 1970, formava-se no sul asiático o Grupo de Estudos Subalternos - com a liderança de Ranajit Guha, um dissidente do marxismo indiano -, cujo principal projeto era "analisar criticamente não só a historiografia colonial da Índia feita por ocidentais europeus, mas também a historiografia eurocêntrica nacionalista indiana” (Grosfoguel, 2008, p.116), bem como a historiografia marxista ortodoxa (Castro-Gómez e Mendieta, 1998). Na década de 1980, os subaltern studies se tornaram conhecidos fora da Índia, especialmente através dos autores Partha Chatterjee, Dipesh Chakrabarty e Gayatri Chakrabarty Spivak³. O termo "subalterno" fora to-

Estes três últimos autores formam, por sua vez, a "tríade sagrada" do pós-colonialismo. Juntamente com Prakash, Chatterjee e Guha, eles "começaram a mostrar que o colonialismo não é somente um 
mado emprestado de Antonio Gramsci e entendido como classe ou grupo desagregado e episódico que tem uma tendência histórica a uma unificação sempre provisória pela obliteração das classes dominantes.

Spivak apresentou o trabalho do grupo ao público estadunidense, sendo ela uma das mais importantes tradutoras de Jaques Derrida. De acordo com Subrahmanyam (2004), sob sua influência os estudos subalternos foram sendo descaracterizados pela introdução excessiva do desconstrutivismo de Deleuze e Derrida ${ }^{4}$. Em 1985, Spivak publicou um artigo que, ao lado dos livros já citados, tornou-se outro cânone do pós-colonialismo: "Pode o subalterno falar?”. É importante reparar que, nesse artigo, a autora faz uma profunda crítica aos intelectuais ocidentais Deleuze e Foucault - a despeito de sua filiação pós-estruturalista e desconstrucionista ${ }^{5}$ - e uma autocrítica aos estudos subalternos, através da reflexão sobre a prática discursiva do intelectual pós-colonial. Para ela, o sujeito subalterno é aquele cuja voz não pode ser ouvida; sua crítica à intelectualidade que pretende falar em seu nome é ao fato de que "nenhum ato de resistência pode ocorrer em nome do subalterno sem que esse ato seja imbricado no discurso hegemônico" (Almeida, 2010, p. 12). Nesse caso, o subalterno permanece silenciado e aparece como constituição de mais um “outro", uma classificação essencialista que acaba por não incorporar a noção de différance ou hibridismo. Para a autora, não só o subalterno não pode falar como também o intelectual pós-colonial não pode fazer isso por ele 6 . Mas como, hoje, poder-se-ia desautorizar Césaire, Fanon, Memmi e Said? O intelectual não poderia também ser um "subalterno"?

$\mathrm{Na}$ década de 1980, o debate pós-colonial foi difundido no campo da crítica literária e dos estudos culturais na Inglaterra e nos Estados Unidos, cujos expoentes mais conhecidos no Brasil são Homi Bhabha (indiano), Stu-

fenômeno econômico e político, mas que possui uma dimensão epistêmica vinculado ao nascimento das ciências humanas, tanto no centro quanto na periferia. Quase todos os autores mencionados argumentaram que as humanidades e as ciências sociais modernas criaram um imaginário sobre o mundo social do "subalterno" (o oriental, o negro, o índio, o camponês) que não somente serviu para legitimar o poder imperial no nível econômico e político, mas também contribuiu para criar os paradigmas epistemológicos dessas ciências e gerar as identidades (pessoais e coletivas) dos colonizadores e colonizados" (Castro-Gómez, 2005a, p. 20).

4 O pós-colonialismo foi visto com desconfiança por alguns autores marxistas devido às influências oriundas do pós-estruturalismo de Foucault, Deleuze, Derrida e Lyotard (Castro-Gómez, 2005a).

A autora também possui forte influência do marxismo, de acordo com Almeida (2010).

O atual projeto coordenado por Boaventura de Sousa Santos, chamado Universidade Popular dos Movimentos Sociais, pretende romper com a lógica de intermediação entre saberes e práticas de militantes e intelectuais militantes. 
art Hall (jamaicano) ${ }^{7}$ e Paul Gilroy (inglês). O local da cultura, Da diáspora e Atlântico negro foram traduzidos para o português e tiveram repercussão nas ciências sociais brasileiras. Em um contexto de globalização, cultura, identidade (classe/etnia/gênero), migração e diáspora apareceram como categorias fundamentais para observar as lógicas coloniais modernas, sendo os estudos pós-coloniais convergentes com os estudos culturais e multiculturais.

Por sua vez, as origens do grupo M/C podem ser remontadas à década de 1990, nos Estados Unidos. Em 1992 - ano de reimpressão do texto hoje clássico de Aníbal Quijano "Colonialidad y modernidad-racionalidad" um grupo de intelectuais latino-americanos e americanistas que lá viviam fundou o Grupo Latino-Americano dos Estudos Subalternos. Inspirado principalmente no Grupo Sul-Asiático dos Estudos Subalternos, o founding statement do grupo foi originalmente publicado em 1993 na revista Boundary 2, editada pela Duke University Press ${ }^{8}$. Em 1998, Santiago Castro-Gómez traduziu o documento para o espanhol como "Manifiesto inaugural del Grupo Latinoamericano de Estudios Subalternos”. A América Latina foi assim inserida no debate pós-colonial:

O trabalho do Grupo de Estudos Subalternos, uma organização interdisciplinar de intelectuais sul-asiáticos dirigida por Ranajit Guha, inspirou-nos a fundar um projeto semelhante dedicado ao estudo do subalterno na América Latina. O atual desmantelamento dos regimes autoritários na América Latina, o final do comunismo e o consequente deslocamento dos projetos revolucionários, os processos de democratização, as novas dinâmicas criadas pelo efeito dos meios de comunicação de massa e a nova ordem econômica transnacional: todos esses são processos que convidam a buscar novas formas de pensar e de atuar politicamente. Por sua vez, a mudança na redefinição das esferas política e cultural na América Latina durante os anos recentes levou a vários intelectuais da região a revisar epistemologias previamente estabelecidas nas ciências sociais e humanidades. A tendência geral para uma democratização outorga prioridade a uma reconceitualização do pluralismo e das condições de subalternidade no interior das sociedades plurais (Grupo Latinoamericano de Estudios Subalternos, 1998, p. 70) ${ }^{9}$.

\footnotetext{
Dirigiu o Centro de Estudos Culturais, em Birmingham.

8 Em 1995 foi reimpresso também em inglês na coletânea "The Pos-modernism Debate in Latin America", editada pela mesma editora, tendo Beverley, Oviedo e Aronna como organizadores.

9 Esta e outras traduções são da autora.
} 
Tal incorporação do "Manifiesto" deu-se em uma coletânea de artigos lançada em 1998, sob a coordenação de Eduardo Mendieta e Santiago Castro-Gómez, intitulada Teorias sin disciplina: latinoamericanismo, poscolonialidad y globalización en debate. Na introdução escrita pelos dois autores, eles explicam a inspiração do grupo:

O Manifesto Inaugural redigido pelo Grupo Latino-americano de Estudos Subalternos incorpora vários dos temas abordados pelo historiador indiano Ranajit Guha, a partir dos quais se pretende avançar para uma reconstrução da história latino-americana das últimas duas décadas. Tal reconstrução ocorreria como uma alternativa ao projeto teórico feito pelos Estudos Culturais ${ }^{10}$ desde os finais dos anos oitenta. Por esta razão, o grupo põe muita ênfase em categorias de ordem política tais como "classe", "nação" ou "gênero", que no projeto dos Estudos Culturais pareciam ser substituídas por categorias meramente descritivas como a de "hibridismo", ou sepultadas sob uma celebração apressada da incidência da mídia e das novas tecnologias no imaginário coletivo (Castro-Gómez e Mendieta, 1998, p. 16).

Já nessa coletânea, a voz mais crítica e radical do grupo, Walter Mignolo, demonstra seu descontentamento também com os estudos subalternos "originais". Na leitura de seus coordenadores,

Walter Mignolo aproveita também alguns elementos das teorias pós-coloniais para realizar uma crítica dos legados coloniais na América Latina. Mas, à diferença de Ileana Rodríguez e de outros membros do Grupo de Estudos Subalternos, Mignolo pensa que as teses de Ranajit Guha, Gayatri Spivak, Homi Bhabha e outros teóricos indianos não deveriam ser simplesmente assumidas e traduzidas para uma análise do caso latino-americano. Ecoando críticas anteriores de Vidal e Klor de Alva, Mignolo afirma que as teorias pós-coloniais têm seu lócus de enunciação nas heranças coloniais do império britânico e que é preciso, por isso, buscar uma categorização crítica do ocidentalismo que tenha seu lócus na América Latina (Castro-Gómez e Mendieta, 1998, p. 17).

Na ocasião Mignolo denuncia o "imperialismo" dos estudos culturais, pós-coloniais e subalternos que não realizaram uma ruptura adequada com autores eurocêntricos (Mignolo, 1998). Para ele, o grupo dos latinos subalternos não deveria se espelhar na resposta indiana ao colonialismo, já que a

${ }^{10}$ Referência aos estudos culturais latino-americanos (Canclini, Brunner, Ortiz, entre outros). 
trajetória da América Latina de dominação e resistência estava ela própria oculta no debate. A história do continente para o desenvolvimento do capitalismo mundial fora diferenciada, sendo a primeira a sofrer a violência do esquema colonial/imperial moderno. Além disso, os latino-americanos migrantes possuem outras relações de colonialidade por parte do novo império estadunidense - ele mesmo tendo sido uma colônia nas Américas.

Devido às divergências teóricas, o grupo latino foi desagregado em 1998, ano em que ocorreram os primeiros encontros entre os membros que posteriormente formariam o Grupo Modernidade/Colonialidade. Grosfoguel (2008), ao narrar seu descontentamento com o projeto do grupo, atribuiu duas razões para sua dissolução ${ }^{11}$. Ambas referem-se à incapacidade do grupo em romper com a episteme - ao seu ver, ainda centrada no Norte - dos estudos regionais estadounidenses e dos estudos subalternos indianos. Descrevendo-se como "um latino a viver nos Estados Unidos" (Grosfoguel, 2008, p. 115), para ele

[o]s latino-americanistas deram preferência epistemológica ao que chamaram os "quatro cavaleiros do Apocalipse", ou seja, a Foucault, Derrida, Gramsci e Guha. Entre estes quatro, contam-se três pensadores eurocêntricos, fazendo dois deles (Derrida e Foucault) parte do cânone pós-estruturalista/pós-moderno ocidental. Apenas um, Rinajit Guha, é um pensador que pensa a partir do Sul. Ao preferirem pensadores ocidentais como principal instrumento teórico traíram o seu objetivo de produzir estudos subalternos. (...). Entre as muitas razões que conduziram à desagregação do Grupo Latino-americano de Estudos Subalternos, uma delas foi a que veio opor os que consideravam a subalternidade uma crítica pós-moderna (o que representa uma crítica eurocêntrica ao eurocentrismo) àqueles que a viam como uma crítica descolonial (o que representa uma crítica do eurocentrismo por parte dos saberes silenciados e subalternizados). Para todos nós que tomamos o partido da crítica descolonial, o diálogo com o Grupo Latino-americano de Estudos Subalternos tornou evidente a necessidade de transcender epistemologicamente - ou seja, de descolonizar - a epistemologia e o cânone ocidentais (Grosfoguel, 2008, p. 116).

Para Grosfoguel, a permanência de Gramsci e Foucault como referências da escola subalterna sul-asiática "acabou por espelhar o apoio dado ao pós-modernismo pelo setor do Grupo Latino-americano de Estudos Subalternos" (Grosfoguel, 2008, p 116). Em suma, nenhum dos dois grupos de estudos

11 A última reunião do grupo foi em outubro de 1998, por ocasião de um congresso sediado na Universidade de Duke, onde se reuniram os latinos e os indianos subalternos (Grosfoguel, 2008). 
subalternos teria conseguido aprofundar e radicalizar sua crítica ao eurocentrismo, um diagnóstico convergente com o de Mignolo. De fato, a maioria dos componentes dos subalternos latinos não migrou para o coletivo modernidade/ colonialidade $^{12}$, que teve na figura de Mignolo um de seus fundadores.

\section{O Grupo Modernidade/Colonialidade e o giro decolonial}

O Grupo Modernidade/Colonialidade foi sendo paulatinamente estruturado por vários seminários, diálogos paralelos e publicações. Ainda no ano de 1998, um importante encontro apoiado pela CLACSO e realizado na Universidad Central de Venezuela, reuniu pela primeira vez Edgardo Lander, Arthuro Escobar, Walter Mignolo, Enrique Dussel, Aníbal Quijano e Fernando Coronil. A partir deste, foi lançada em 2000 uma das publicações coletivas mais importantes do M/C: La colonialidad del saber: eurocentrismo y ciencias sociales. No mesmo ano de 1998, Ramon Grosfóguel e Agustín Lao-Montes reuniram em Binghamton, para um congresso internacional, Enrique Dussel, Walter Mignolo, Aníbal Quijano e Immanuell Wallerstein. Nesse congresso foi discutida pelos quatro autores a herança colonial na América Latina, a partir da análise do sistema-mundo de Wallerstein (Castro-Gómez e Grosfoguel, 2007).

Em 1999, ocorreu na Pontificia Universidad Javeriana, Colômbia, um simpósio internacional organizado por Santiago Castro-Gómez e Oscar Guardiola, que os reuniu com Mignolo, Lander, Coronil, Quijano, Zulma Palermo e Freya Schiwy. Selava-se então a cooperação entre a Universidad Javeriana de Bogotá, Duke University, University of North Carolina e a Universidad Andina Simón Bolívar ${ }^{13}$.

Nos anos 2000, ocorreram sete reuniões/eventos oficiais do grupo (nos anos 2001, 2002, 2003, 2004, 2006), o qual incorporou e dialogou com os seguintes nomes: Javier Sanjinés ${ }^{14}$, Catherine Walsh, Nelson Maldonado-Torres, José David Saldívar, Lewis Gordon, Boaventura de Sousa Santos,

12 O Grupo Latino-Americano de Estudos Subalternos foi originalmente formado por lleana Rodríguez, John Berverley, Robert Carr, José Rabasa e Javier Sanjinés. A história de sua formação e dissolução mereceria um artigo à parte. O grupo foi formado em um diálogo sul-sul com os indianos em uma universidade do norte, como afirma a nicaraguense lleana Rodríguez. O leque de influências e trânsitos do grupo é bastante amplo: estudos subalternos, estudos culturais, literários, pós-modernos e críticos latino-americanos, pós-estruturais, pós-marxistas, feministas. Ele foi responsável por inserir a América Latina no debate pós-colonial, marcando suas diferenças com o projeto asiático. lleana Rodríguez é a editora da coletânea The Latin American subaltern studies reader, publicada em 2001 pela Duke University Press.

${ }^{3}$ Desse evento resultaram as primeiras publicações do grupo: Pensar (en) los intersticios. Teoría y práctica de la crítica poscolonial (1999) e La reestructuración de las ciencias sociales en América Latina (2000).

14 Anteriormente vinculado ao Grupo Latino-Americano dos Estudos Subalternos. 
Margarita Cervantes de Salazar, Libia Grueso e Marcelo Fernández Osco (Castro-Gómez e Grosfoguel, 2007; Mignolo, 2010). Outros estudiosos associados ao grupo são Jorge Sanjinés, Ana Margarita Cervantes-Rodríguez, Linda Alcoff, Eduardo Mendieta, Elina Vuola, Marisa Belausteguigoitia e Cristina Rojas (Escobar, 2003).

Abaixo, segue um quadro no qual é possível identificar as diferentes áreas, nacionalidade, local e país de trabalho de alguns de seus principais membros:

Quadro 1. Perfil dos membros do Grupo Colonialidade/Modernidade ${ }^{15}$

\begin{tabular}{c|c|c|c}
\hline integrante & área & nacionalidade & universidade onde leciona \\
\hline Aníbal Quijano & sociologia & peruana & $\begin{array}{c}\text { Universidad Nacional } \\
\text { de San Marcos, Peru }\end{array}$ \\
\hline Enrique Dussel & filosofia & argentina & $\begin{array}{c}\text { Universidad Nacional } \\
\text { Autónoma de México }\end{array}$ \\
\hline Walter Mignolo & semiótica & argentina & Duke University, EUA \\
\hline Immanuel Wallerstein & sociologia & estadounidense & Yale University, EUA \\
\hline Santiago Castro-Gómez & filosofia & colombiana & Pontificia Universidad Javeriana, Colômbia \\
\hline Nelson Maldonado-Torres & filosofia & porto-riquenha & University of California, Berkeley, EUA \\
\hline Ramón Grosfóguel & sociologia & porto-riquenha & University of California, Berkeley, EUA \\
\hline Edgardo Lander & sociologia & venezuelana & Universidad Central de Venezuela \\
\hline Arthuro Escobar & antropologia & colombiana & University of North Carolina, EUA \\
\hline Fernando Coronil & antropologia & venezuelana & University of New York, EUA \\
\hline Catherine Walsh & linguística & estadounidense & Universidad Andina Simón Bolívar, Equador \\
\hline Boaventura Santos & direito & portuguesa & Universidade de Coimbra, Portugal \\
\hline Zulma Palermo & semiótica & argentina & Universidad Nacional de Salta, Argentina \\
\hline
\end{tabular}

*Falecido em 2011.

Fonte: Elaboração própria a partir de pesquisa de dados institucionais e pessoais disponíveis na internet

Muitos desses integrantes já haviam desenvolvido, desde os anos 1970, linhas de pensamento próprias, como é o caso de Dussel e a Filosofia da Libertação, Quijano e a Teoria da Dependência, e Wallerstein e a Teoria do Sistema-Mundo. A identidade grupal do M/C acabou herdando essas e

\footnotetext{
15 Este quadro não esgota as diversas áreas do conhecimento que seus integrantes transitam, nem as várias universidades em que atuam como visitantes. Da mesma forma, a seleção dos principais membros do grupo pode ser questionada. Sobre a pouca participação das mulheres no grupo - que contradiz com o diálogo aberto e constante com o feminismo especialmente latino - ver um mea-culpa por Arthuro Escobar (2003).
} 
outras influências do pensamento crítico latino-americano do século XX. Para Escobar, a genealogia de pensamento do grupo inclui

[a] Teologia da Libertação desde os sessenta e setenta; os debates na filosofia e ciência social latino-americana sobre noções como filosofia da libertação e uma ciência social autônoma (por ex., Enrique Dussel, Rodolfo Kusch, Orlando Fals Borda, Pablo Gonzáles Casanova, Darcy Ribeiro); a teoria da dependência; os debates na América Latina sobre a modernidade e pós- modernidade dos oitenta, seguidos pelas discussões sobre hibridismo na antropologia, comunicação nos estudos culturais nos noventa; e, nos Estados Unidos, o grupo latino-americano de estudos subalternos. O grupo modernidade/colonialidade encontrou inspiração em um amplo número de fontes, desde as teorias críticas europeias e norte-americanas da modernidade até o grupo sul-asiático de estudos subalternos, a teoria feminista chicana, a teoria pós-colonial e a filosofia africana; assim mesmo, muitos de seus membros operaram em uma perspectiva modificada de sistema-mundo. Sua principal força orientadora, no entanto, é uma reflexão continuada sobre a realidade cultural e política latino-americana, incluindo o conhecimento subalternizado dos grupos explorados e oprimidos (Escobar, 2003, p.53).

$\mathrm{O} \mathrm{M} / \mathrm{C}$ é considerado por Escobar como um "programa de investigação" (Escobar, 2003, p.53). Com pouco mais de dez anos de existência, o grupo compartilha noções, raciocínios e conceitos que lhe conferem uma identidade e um vocabulário próprio, contribuindo para a renovação analítica e utópica das ciências sociais latino-americanas do século XXI. Sem a pretensão de esgotar a riqueza de sua argumentação, será apresentado um elenco de conceitos chaves relativamente originais. De início, ressalta-se que tal apresentação possui o fim de familiarizar o leitor com as propostas do grupo, sendo essas absolutamente passíveis de críticas e contra-argumentos. Essa empreitada foi propositalmente aqui evitada, tornando-se um possível objeto de outro trabalho.

\section{Colonialidade do poder}

A colonialidade do poder é um conceito desenvolvido originalmente por Aníbal Quijano, em 1989, e amplamente utilizado pelo grupo. Ele exprime uma constatação simples, isto é, de que as relações de colonialidade nas esferas econômica e política não findaram com a destruição do colonialismo. $\mathrm{O}$ conceito possui uma dupla pretensão. Por um lado, denuncia "a continuidade 
das formas coloniais de dominação após o fim das administrações coloniais, produzidas pelas culturas coloniais e pelas estruturas do sistema-mundo capitalista moderno/colonial" (Grosfoguel, 2008, p.126). Por outro, possui uma capacidade explicativa que atualiza e contemporiza processos que supostamente teriam sido apagados, assimilados ou superados pela modernidade. Esse entendimento é bem explicado por Grosfoguel (2008, p. 126),

A expressão "colonialidade do poder" designa um processo fundamental de estruturação do sistema-mundo moderno/colonial, que articula os lugares periféricos da divisão internacional do trabalho com a hierarquia étnico-racial global e com a inscrição de migrantes do Terceiro Mundo na hierarquia étnico-racial das cidades metropolitanas globais. Os Estados-nação periféricos e os povos não-europeus vivem hoje sob o regime da "colonialidade global" imposto pelos Estados Unidos, através do Fundo Monetário Internacional, do Banco Mundial, do Pentágono e da OTAN. As zonas periféricas mantêm-se numa situação colonial, ainda que já não estejam sujeitas a uma administração colonial.

O conceito de colonialidade foi estendido para outros âmbitos que não só o do poder. Assim, Mignolo (2010, p.12) sugere que a matriz colonial do poder "é uma estrutura complexa de níveis entrelaçados", como abaixo se vê:

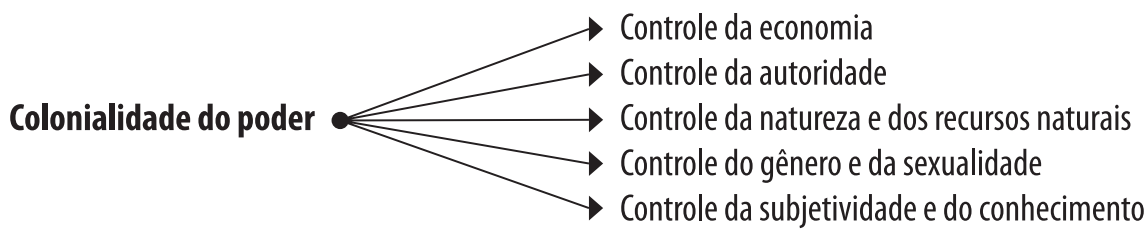

A colonialidade se reproduz em uma tripla dimensão: a do poder, do saber e do ser ${ }^{16}$. E mais do que isso: a colonialidade é o lado obscuro e necessário da modernidade; é a sua parte indissociavelmente constitutiva (Mignolo, 2003, p. 30). É precisamente desse diagnóstico - elaborado especialmente por Quijano, Wallerstein e Mignolo - que deriva o nome do grupo. A modernidade, estando "intrinsecamente associada à experiência colonial" (Maldonado-

\footnotetext{
${ }^{16}$ A Colonialidade do Poder e do Saber ganhou várias elaborações do grupo, enquanto que a Colonialidade do Ser, primeiramente pensada por Mignolo e posteriormente desenvolvida por Maldonado-Torres, não foi recebida com entusiasmo (Maldonado-Torres, 2008).
} 
-Torres, 2008, p.84), não é capaz de apagá-la: não existe modernidade sem colonialidade (Quijano, 2000, p. 343). De outro lado, não poderia haver uma economia-mundo capitalista sem as Américas (Quijano e Wallerstein, 1992).

\section{Modernidade/colonialidade}

É possível situar o contexto de emergência da colonialidade e da colonialidade do poder: guerra, genocídio e conquista das Américas ${ }^{17}$ (Maldonado-Torres, 2008, p. 136). E eis que aqui surgiu um tipo de classificação social próspera para a empresa colonial: a ideia de raça. A construção da diferença, da superioridade e da pureza de sangue da raça branca é um feito inédito:

A colonialidade é um dos elementos constitutivos e específicos do padrão mundial de poder capitalista. Se funda na imposição de uma classificação racial/étnica da população do mundo como pedra angular do dito padrão de poder e opera em cada um dos planos, âmbitos e dimensões materiais e subjetivas, da existência social cotidiana e da escala social. Origina-se e mundializa-se a partir da América (Quijano, 2000, p. 342).

Para o autor, raça, gênero e trabalho foram as três linhas principais de classificação que constituíram a formação do capitalismo mundial colonial/ moderno no século XVI (Quijano, 2000, p. 342). É nessas três instâncias que as relações de exploração/dominação/conflito estão ordenadas. A identificação dos povos de acordo com suas faltas ou excessos é uma marca fundamental da diferença colonial, produzida e reproduzida pela colonialidade do poder - em particular, o poder colonial (Mignolo, 2003, p. 39) -, do saber e do ser (Maldonado-Torres, 2008, p. 147). O que o conceito de colonialidade do poder traz de novo é a leitura da raça e do racismo como "o princípio organizador que estrutura todas as múltiplas hierarquias do sistema-mundo" (Grosfoguel, 2008, p. 123). Se a raça é uma categoria mental da modernidade, tem-se que seu sentido moderno não tem história conhecida antes da América (Quijano, 2005, p. 1). Nessa mesma linha, Dussel argumenta que a modernidade, assentada e iniciada nesses pilares, justifica uma "práxis irracional da violência" (Dussel, 2000, p. 49). A modernidade é um "mito" que oculta a colonialidade e se desenvolve da seguinte forma:

17 É a partir desta concepção do início da modernidade que Maldonado-Torres (2008) desenvolve o conceito de Colonialidade do Ser. Inspirando-se em Fanon e Dussel, recupera a ideia deste último de que o ego conquiro (yo conquistador) foi a proto-história do ego cogito cartesiano. 
1. A civilização moderna autodescreve-se como mais desenvolvida e superior (o que significa sustentar inconscientemente uma posição eurocêntrica). 2. A superioridade obriga a desenvolver os mais primitivos, bárbaros, rudes, como exigência moral. 3 . O caminho de tal processo educativo de desenvolvimento deve ser aquele seguido pela Europa (é, de fato, um desenvolvimento unilinear e à europeia o que determina, novamente de modo inconsciente, a "falácia desenvolvimentista"). 4. Como o bárbaro se opõe ao processo civilizador, a práxis moderna deve exercer em último caso a violência, se necessário for, para destruir os obstáculos dessa modernização (a guerra justa colonial). 5. Esta dominação produz vítimas (de muitas e variadas maneiras), violência que é interpretada como um ato inevitável, e com o sentido quase-ritual de sacrifício; o herói civilizador reveste a suas próprias vítimas da condição de serem holocaustos de um sacrifício salvador (o índio colonizado, o escravo africano, a mulher, a destruição ecológica, etecetera). 6. Para o moderno, o bárbaro tem uma "culpa" (por opor-se ao processo civilizador) que permite à "Modernidade" apresentar-se não apenas como inocente mas como "emancipadora" dessa "culpa" de suas próprias vítimas. 7. Por último, e pelo caráter "civilizatório" da "Modernidade", interpretam-se como inevitáveis os sofrimentos ou sacrifícios (os custos) da "modernização" dos outros povos "atrasados" (imaturos), das outras raças escravizáveis, do outro sexo por ser frágil, etecetera (Dussel, 2000, p. 49).

Essas e outras elaborações permitiram então a reconfiguração da ideia original de sistema-mundo de Wallerstein, pensado agora em termos de "sistema-mundo moderno/colonial" ou, provocativamente, como o que Grosfoguel chamou de "sistema mundo europeu/euro-norte-americano moderno/capitalista/colonial/patriarcal” (Grosfoguel, 2008, p. 113).

Para este último, "às Américas chegou o homem heterossexual/branco/ patriarcal/cristão/militar/capitalista europeu” e, com ele, a reprodução dos padrões hierárquicos globais já existentes. A inserção do elemento colonial/ racial/moderno na noção de sistema-mundo de Wallerstein permitiu então desvelar a diferença colonial, até então não considerada pelo próprio autor (Mignolo, 2003). Em suma, o fundamento da modernidade/colonialidade está no descobrimento e na invenção da América - para Dussel, Mignolo, Quijano/Wallerstein ; ela é uma origem, "tão origem” como fora a Grécia para a civilização ocidental (Mignolo, 2003, p. 57). Até o século XVI não havia diferença colonial, mas diferença imperial ${ }^{18}$ : os bárbaros eram impe-

18 A noção de "diferença imperial" remete a um processo intra-hierárquico dentro dos próprios impérios capitalistas, ocidentais e cristãos, como, por exemplo, a constituição do Sul da Europa - hoje também partícipe da ideia sociológica de Sul Global. 
riais turcos, mouros, chineses, russos (Mignolo, 2003, p. 42). Para Dussel, a América não somente foi a primeira periferia do sistema-mundo como também a primeira oportunidade de acumulação primitiva do capital ${ }^{19}$ (Castro-Gómez, 2005a).

A noção de diferença colonial desenvolvida por Mignolo (2002, 2003) projeta muita importância ao lócus de enunciação dessa mesma diferença. E aqui se tem outra dimensão fundamental para o grupo: a dimensão epistêmica e epistemológica, isto é, a colonialidade do saber.

\section{Geopolítica do conhecimento}

O problema da colonialidade do saber é um dos mais recorrentes dentro das discussões do $\mathrm{M} / \mathrm{C}$ e está diretamente associado àquilo que Mignolo (2002) chamou de "diferença colonial e geopolítica do conhecimento". Sendo paralela à própria geopolítica da economia, a noção de violência epistêmica elaborada por Foucault tornou-se insuficiente para captar o silêncio oriundo do racismo epistêmico (Maldonado-Torres, 2008) ou a negação da alteridade epistêmica (Castro-Gómez, 2005b). Para Castro-Gómez, a noção de Foucault "deve ser ampliada para o âmbito de macroestruturas de longa duração (Braudel/Wallerstein), de tal maneira que permita visualizar o problema da "invenção do outro" de uma perspectiva geopolítica" (Castro-Gómez, 2005a, p. 4). O que Foucault não conseguiu capturar em sua denúncia foi o eurocentrismo e o colonialismo, duas faces da mesma moeda. O eurocentrismo é uma lógica fundamental para a reprodução da colonialidade do saber, como explica Quijano:

A elaboração intelectual do processo de modernidade produziu uma perspectiva de conhecimento e um modo de produzir conhecimento que demonstram o caráter do padrão mundial de poder: colonial/moderno, capitalista e eurocentrado. Essa perspectiva e modo concreto de produzir conhecimento se reconhecem como eurocentrismo. Eurocentrismo é, aqui, o nome de uma perspectiva de conhecimento cuja elaboração sistemática começou na Europa Ocidental antes de mediados do século XVII, ainda que algumas de suas raízes são sem dúvida mais velhas, ou mesmo antigas, e que nos séculos seguintes se tornou mundialmente hegemônica percorrendo o mesmo fluxo do domínio da Europa burguesa. Sua constituição ocorreu associada à específica secularização burguesa do pensamento europeu e à experiência e às necessidades do

19 A importância da América para a acumulação primitiva do capital já se encontra nos escritos marxianos, referência fundamental para o pensamento de Dussel. 
padrão mundial de poder capitalista, colonial/moderno, eurocentrado, estabelecido a partir da América (Quijano, 2005, p. 9).

A diferença colonial epistêmica é cúmplice do universalismo, sexismo e racismo. Nesse debate, agregou-se a noção do filósofo colombiano Castro-Gómez de "hybris del punto cero" (Castro-Gómez, 2005c). O "ponto zero" é um ponto de partida de observação, supostamente neutro e absoluto, no qual a linguagem científica desde o Iluminismo assume-se "como a mais perfeita de todas as linguagens humanas" e que reflete "a mais pura estrutura universal da razão" (Castro-Gómez, 2005c, p. 14). A lógica do "ponto zero" é eurocentrada e "presume a totalização da gnose ocidental, fundada no grego, no latim e nas seis línguas ${ }^{20}$ modernas imperiais europeias" (Mignolo, 2007b, p. 29). Ela funda e sustenta a razão imperial (teo-ego-politicamente):

Trata-se, então, de uma filosofia na qual o sujeito epistêmico não tem sexualidade, gênero, etnia, raça, classe, espiritualidade, língua, nem localização epistêmica em nenhuma relação de poder, e produz a verdade desde um monólogo interior consigo mesmo, sem relação com ninguém fora de si. Isto é, trata-se de uma filosofia surda, sem rosto e sem força de gravidade. O sujeito sem rosto flutua pelos céus sem ser determinado por nada nem por ninguém (...). Será assumida pelas ciências humanas a partir do século XIX como a epistemologia da neutralidade axiológica e da objetividade empírica do sujeito que produz conhecimento científico (Grosfoguel, 2007, p. 64-65).

O núcleo deste diagnóstico, obviamente, não é uma constatação original do grupo, assim como também não o é a crítica da modernidade ocidental. A novidade aqui é que o grupo $\mathrm{M} / \mathrm{C}$, assim como outros movimentos teóricos, entrou naquilo que Visvanathan (2004) chamou de "Guerra da Ciência". O movimento de descobrimento e de revalorização das teorias e epistemologias do sul tem crescido nos últimos anos em diversas áreas e universidades do mundo. Como defende Mignolo (2003), não se trata da substituição de um novo paradigma nos termos de Kuhn, mas do surgimento de "paradigmas outros". Se para Habermas a modernidade é um projeto inacabado, para o

20 Inglês, alemão, francês, italiano, espanhol e português (Mignolo, 2010). 
grupo M/C a descolonização também o é21. Diferentemente da modernidade, a colonialidade não é um ponto de chegada (Mignolo, 2003).

\section{Giro decolonial}

"Giro decolonial" é um termo cunhado originalmente por Nelson Maldonado-Torres em $2005^{22}$ e que basicamente significa o movimento de resistência teórico e prático, político e epistemológico, à lógica da modernidade/colonialidade. A decolonialidade aparece, portanto, como o terceiro elemento da modernidade/colonialidade. Para Mignolo, "a conceitualização mesma da colonialidade como constitutiva da modernidade é já o pensamento de-colonial em marcha" (Mignolo, 2008, p. 249). Mas, para ele, a origem do pensamento decolonial é mais remota, emergindo como contrapartida desde a fundação da modernidade/colonialidade. Seria possível, portanto, considerar Wama Pomam de Ayala - do vice-reinado peruano que enviou ao rei Felipe III em 1616 sua Nueva crónica y buen gobierno - e Otabbah Cugoano - um escravo liberto que publicou em Londres, em 1787, Thoughts and sentiments on the evil of slavery - como os primeiros autores de tratados políticos decoloniais, que não usufruem o mesmo prestígio daqueles escritos por Hobbes, Locke ou Rousseau.

Vale reproduzir o raciocínio de Mignolo ao enaltecer e diferenciar o pensamento decolonial:

Colonialidade e descolonialidade introduzem uma fratura entre a pós-modernidade e a pós-colonialidade como projetos no meio do caminho entre o pensamento pós-moderno francês de Michel Foucault, Jacques Lacan e Jacques Derrida e quem é reconhecido como a base do cânone pós-colonial: Edward Said, Gayatri Spivak e Hommi Bhabba. A descolonialidade - em contrapartida - arranca de outras fontes. Desde a marca descolonial implícita na Nueva Crónica y Buen Gobierno de Guamán Poma de Ayala; no tratado político de Ottobah Cugoano; no ativismo e crítica decolonial de Mahatma Ghandi; na fratura do Marxismo em seu encontro com o legado

${ }^{21}$ Trata-se da trans-modernidade defendida por Dussel e explicada na próxima seção: “Em oposição ao projeto de Habermas, que propõe como tarefa central a necessidade de terminar o projeto inacabado e incompleto da modernidade, a transmodernidade de Dussel é o projeto para terminar, através de um largo processo, o inacabado e incompleto projeto da decolonização" (Grosfoguel, 2007, p.73).

22 O autor organizou em 2005 um encontro em Berkeley chamado Mapping Decolonial Turn, onde o grupo M/C dialogou com um grupo de filósofos caribenhos e filósofas latinas. Essa reunião foi fundamental para constituir a decolonialidade como o terceiro elemento da modernidade/colonialidade (Mignolo, 2010). 
colonial nos Andes, no trabalho de José Carlos Mariátegui; na política radical, o giro epistemológico de Amilcar Cabral, Aimé Césaire, Frantz Fanon, Rigoberta Menchú, Gloria Anzaldúa, entre outros (Mignolo, 2010, p. 14-15).

Em suas palavras, Tawantinsuyu, Anáhuac e o Caribe Negro seriam as “Grécias" e "Romas” das Américas (Mignolo, 2003, p. 32). Isso permite traçar outra genealogia do argumento pós-colonial, que também haveria de incorporar a reflexão dos movimentos sociais:

A genealogia global do pensamento decolonial (realmente outra em relacão com a genealogia da teoria pós-colonial) até Mahatma Gandhi, W. E. B. Dubois, Juan Carlos Mariátegui, Amílcar Cabral, Aimé Césaire, Frantz Fanon, Fausto Reinaga, Vine Deloria Jr., Rigoberta Menchú, Gloria Anzaldúa, o movimento Sem Terras no Brasil, os zapatistas em Chiapas, os movimentos indígenas e afros na Bolívia, Equador e Colômbia, o Fórum Social Mundial e o Fórum Social das Américas. A genealogia do pensamento decolonial é planetária e não se limita a indivíduos, mas incorpora nos movimentos sociais (o qual nos remete aos movimentos sociais indígenas e afros) (Mignolo, 2008, p. 258).

O pensamento decolonial é uma elaboração posterior àquilo que em outro lugar Mignolo chamou de "pensamento fronteiriço":

O pensamento fronteiriço, desde a perspectiva da subalternidade colonial, é um pensamento que não pode ignorar o pensamento da modernidade, mas que não pode tampouco subjugar-se a ele, ainda que tal pensamento moderno seja de esquerda ou progressista. O pensamento fronteiriço é o pensamento que afirma o espaço de onde o pensamento foi negado pelo pensamento da modernidade, de esquerda ou de direita (Mignolo, 2003, p. 52).

O pensamento fronteiriço resiste às cinco ideologias da modernidade: cristianismo, liberalismo, marxismo, conservadorismo e colonialismo (Mignolo, 2003). O autor reconhece, no entanto, a importância de autores que no contexto da modernidade eurocêntrica denunciaram o sofrimento humano, como Las Casas e Marx. A denúncia ao eurocentrismo do marxismo, realizada também por Lander (2006), assimila as versões do marxismo periférico, como as de Mariátegui e Gramsci - este em menor medida. Ao passo que 
o primeiro incorporou a questão indígena - escola revitalizada pelo vice-presidente e sociólogo boliviano Álvaro García Linera -, a legitimidade de Gramsci residiria no seu lugar de fala desde a periferia da própria Europa - mesmo argumento aplicado ao sociólogo português Sousa Santos. Tal rejeição seletiva ao marxianismo e marxismo - pela cegueira ou cumplicidade com o colonialismo ${ }^{23}$ e com o eurocentrismo ${ }^{24}$ - é observada fortemente em Mignolo e Sousa Santos ${ }^{25}$. Ambos rejeitam a validade do marxismo como a única utopia radical, crítica e anticapitalista, para o século XXI.

As origens da ideia de decolonialidade estavam já contidas em Quijano e Dussel. O primeiro, desde seu artigo no qual desenvolve a ideia de colonialidade do poder, é claro quanto à necessidade de descolonização; Dussel, por sua vez, trouxe a noção de trans-modernidade:

A Modernidade nasce realmente em 1492: essa é a nossa tese. Sua real superação (como subsuntion e não meramente como Aufhebung hegeliana) é a subsunção de seu caráter emancipador racional europeu transcendido como projeto mundial de libertação de sua Alteridade negada: a Trans-Modernidade (como novo projeto de libertação político, econômico, ecológico, erótico, pedagógico, religioso, etecetera) (Dussel, 2000, p. 50-51).

Relaciona-se com o projeto de decolonização na medida em que esta aspira romper com a lógica monológica da modernidade. Pretende fomentar a transmodernidade: um conceito que também deve se entender como um convite ao diálogo e não como um novo universal abstrato imperial. A transmodernidade é um convite a pensar a modernidade/colonialidade de forma crítica, desde posições e de acordo com as múltiplas experiências de sujeitos que sofrem de distintas formas a colonialidade do poder, do saber e do ser. A transmodernidade envolve, pois, una ética dialógica radical e um cosmopolitismo de-colonial crítico (Maldonado-Torres, 2007, p. 162).

${ }^{23}$ Para Castro-Gómez, um dos problemas do marxismo é que "o colonialismo é um efeito colateral da expansão europeia pelo mundo e, neste sentido, forma parte de um trânsito necessário até o advento mundial do comunismo" (Castro-Gómez, 2005a, p. 17).

24 Atualmente, alguns membros do grupo como Maldonado-Torres e Mignolo, destinam-se este tipo de crítica a Slavoj Žižek, pensador contemporâneo marxista que tardiamente entrou na moda acadêmica do Brasil.

25 Os dois autores possuem um estilo parecido de escrita, ainda que Mignolo seja teoricamente mais sofisticado que Sousa Santos. 
A trans-modernidade de Dussel propicia "a pluriversalidade como projeto universal” de Mignolo (2010, p. 17). Desprendimento, abertura, de-linking, desobediência, vigilância e suspeição epistêmicas são estratégias para a decolonização, de-colonização ou descolonização epistemológica.

Por fim, resta a explicação de um detalhe referente à identidade do coletivo M/C. Trata-se da sugestão feita por Catherine Walsh para a utilização da expressão "decolonização" - com ou sem hífen - e não "descolonização" (Mignolo, 2008, 2010). A supressão da letra "s" marcaria a distinção entre o projeto decolonial do Grupo Modernidade/Colonialidade e a ideia histórica de descolonização, via libertação nacional durante a Guerra Fria. Além disso, insere-se em outra genealogia de pensamento ${ }^{26}$, sendo o constitutivo diferencial do $\mathrm{M} / \mathrm{C}$, reivindicado por Mignolo:

O projeto des-colonial difere também do projeto pós-colonial (...). A teoria pós-colonial ou os estudos pós-coloniais estão entre a teoria crítica da Europa (Foucault, Lacan y Derrida), sobre cujo pensamento se construiu a teoria pós-colonial e/ou estudos pós-coloniais, e as experiências da elite intelectual nas ex-colônias inglesas na Ásia e África do Norte (Mignolo, 2010, p. 19).

Basicamente, a decolonização é um diagnóstico e um prognóstico afastado e não reivindicado pelo mainstream do pós-colonialismo, envolvendo diversas dimensões relacionadas com a colonialidade do ser, saber e poder. Ainda que assuma a influência do pós-colonialismo, o Grupo Modernidade/ Colonialidade recusa o pertencimento e a filiação a essa corrente. O mesmo se aplica às outras influências recebidas que possibilitaram o surgimento e o desenvolvimento da construção teórica do grupo. Contudo, aquilo que é original dos estudos decoloniais parece estar mais relacionado com as novas lentes colocadas sobre velhos problemas latino-americanos do que com o elenco desses problemas em si.

\section{Considerações finais}

O processo de decolonização não deve ser confundido com a rejeição da criação humana realizada pelo Norte global e associado com aquilo que seria genuinamente criado no Sul, no que pese práticas, experiências, pen-

${ }^{26}$ O mesmo tipo de argumento é usado para a preferência da palavra "libertação"à "emancipação", típica da Escola de Frankfurt, que ainda estaria comprometida com a modernidade. 
samentos, conceitos e teorias. Ele pode ser lido como contraponto e resposta à tendência histórica da divisão de trabalho no âmbito das ciências sociais (Alatas, 2003), na qual o Sul Global fornece experiências, enquanto o Norte Global as teoriza e as aplica (Connell, 2012). Nesse sentido, é revelador que ao esforço de teorização no Brasil e na América Latina caibam os rótulos de "pensamento" e não "teoria” social e política.

Atualmente, diversos autores e autoras, situados tanto nos centros quanto nas periferias da produção da geopolítica do conhecimento, questionam o universalismo etnocêntrico, o eurocentrismo teórico, o nacionalismo metodológico, o positivismo epistemológico e o neoliberalismo científico contidos no mainstream das ciências sociais. Essa busca tem informado um conjunto de elaborações denominadas Teorias e Epistemologias do Sul (Santos e Meneses, 2010; Connell, 2007), as quais procuram valorizar e descobrir perspectivas trans-modernas, no sentido de Dussel, para a decolonização das ciências sociais. Assim, as vozes do M/C acabam somando-se a um movimento mundial em curso de refundação e descolonização epistemológica ${ }^{27}$.

O papel e a importância da teoria repousam não somente na sua capacidade explicativa mas também no seu potencial normativo. Se toda teoria serve para algo ou para alguém, é razoável partir do princípio de que ela reproduz relações de colonialidade do próprio poder. Historicamente, a teoria e a filosofia política foram predominantemente pensadas no Norte e para o Norte. Por um lado, ela serviu como pilar fundamental para a arquitetura da exploração, dominação e colonização dos povos não situados no Ocidente exemplar. Por outro, o Ocidente foi capaz de reagir desde dentro, improvisando teorias outras, críticas e contra-hegemônicas ${ }^{28}$. Essa marginalidade teórica dialoga com as versões periféricas e subalternas produzidas fora do Norte. Dessa perspectiva, decolonizar a teoria, em especial a teoria política, é um dos passos para decolonização do próprio poder.

Este artigo trabalhou com uma produção teórica ainda marginal e que claramente contém horizontes de utopia política e radicalismo intelectual. Suas maiores contribuições são a identificação, a interpretação e a teorização dos processos de modernidade/colonialidade/decolonialidade, a partir da

\footnotetext{
${ }^{27}$ Ver especialmente as coletâneas de Santos (2005, 2006); Jones (2006); Navaz e Castillo (2008); Santos e Meneses (2010).

28 Ainda assim: quão radical é a democracia radical de Chantal Mouffe? Qual é o sujeito de Axel Honneth? Onde entram os direitos da natureza no paradigma dual de Nancy Fraser? Onde está a violência na esfera pública de Jürgen Habermas? Em aberto.
} 
“invenção" da América (só posteriormente, Latina) no século XVI. Para os estudiosos da ciência e da teoria política no Brasil, o conceito de colonialidade do poder é de particular importância.

O Grupo Modernidade/Colonialidade possui méritos importantes de serem destacados. Trata-se de um trabalho reflexivo coletivo, transdisciplinar e engajado ${ }^{29}$, que ao mesmo tempo em que oferece novas leituras analíticas, é capaz de pensar em termos propositivos e programáticos. Com isso, projeta sua importância para o mundo e para a América Latina, renovando utopia e crítica nas ciências sociais latino-americanas. Sua proposta é ao mesmo tempo provocativa e desconfortável, dado o tom de indeferimento radical às conquistas do passado via liberalismo e marxismo e às influências de escolas que o permitiram, afinal, existir. Essa sensação deve-se ao fato de que seus autores dialogam de uma maneira seletiva com os nomes clássicos - modernos e contemporâneos - das ciências sociais e da filosofia, geralmente, apontando suas deficiências na cobrança de um elemento (colonial) sobre o qual o próprio contexto demandava iluminação. Entretanto, uma de suas estratégias consiste mesmo na revisão do que é considerado clássico.

Dentre as contribuições consistentes do grupo, estão as tentativas de marcar: (a) a narrativa original que resgata e insere a América Latina como o continente fundacional do colonialismo, e, portanto, da modernidade; (b) a importância da América Latina como primeiro laboratório de teste para o racismo a serviço do colonialismo; (c) o reconhecimento da diferença colonial, uma diferença mais difícil de identificação empírica na atualidade, mas que fundamenta algumas origens de outras diferenças; (d) a verificação da estrutura opressora do tripé colonialidade do poder, saber e ser como forma de denunciar e atualizar a continuidade da colonização e do imperialismo, mesmo findados os marcos históricos de ambos os processos; (e) a perspectiva decolonial, que fornece novos horizontes utópicos e radicais para o pensamento da libertação humana, em diálogo com a produção de conhecimento.

Muitos dos pontos problemáticos das propostas do coletivo talvez surjam desses mesmos horizontes, de diagnósticos romanceados e reprodutores de maniqueísmos. Domingues, em sua crítica a Mignolo, destaca as seguintes deficiências de seu projeto: "inversão das polaridades da teoria da moder-

29 Segundo Escobar (2003), todos os integrantes do grupo possuem algum tipo de envolvimento ou militância política. 
nização, descarte integral da modernidade e sobrevalorização da questão étnica", assim como a desconsideração da luta de classes (Domingues, 2011, p. 82). Além disso, faltaria ao grupo um debate mais sistemático com as ciências sociais, em particular a latino-americana. As críticas de Domingues são em parte pertinentes, mas não ao ponto de invalidar a produção acadêmica do grupo, cuja referência para o debate sobre modernidade e colonialidade na América Latina é hoje indispensável. Na esteira da crítica de Domingues, existe um forte intuito de validar sua tese individual acerca dos "giros modernizadores". Em defesa do grupo, pode-se afirmar que não está em questão a rejeição total da modernidade, mas sim o convite à observação e à construção de modernidades alternativas ao único modelo ocidental. Já a desconsideração dos aspectos econômicos em detrimento dos aspectos culturais não pode ser afirmada, uma vez que a própria noção de colonialidade está assentada na denúncia ao capitalismo e que a produção passada e presente de muitos dos seus autores carregam as influências de teorias preocupadas com a exploração/opressão econômica - libertação, dependência, sistema-mundo.

Entretanto, uma questão importante que não povoa o imaginário pós-colonial e decolonial do Grupo Modernidade/Colonialidade é a discussão sobre e com o Brasil. Esse é um ponto problemático, já que a colonização portuguesa - a mais duradoura empreitada colonial europeia - trouxe especificidades ao caso brasileiro em relação ao resto da América. O Brasil aparece quase como uma realidade apartada da realidade latino-americana. É significativo o fato de não haver um(a) pesquisador(a) brasileiro(a) associado ao grupo $^{30}$, assim como nenhum cientista político - brasileiro ou não. Também o grupo foi atingido pelo "complexo de Colombo"31 (Melman, 2000). Assim, ele privilegia a análise da América hispânica em detrimento da portuguesa e chama pouca atenção aos processos de colonialidade e subimperialismo dentro do continente, à exceção dos Estados Unidos.

E, de fato, alguns textos esbarram na romantização dos oprimidos e explorados, apologia do sujeito autóctone/original, descontrutivismo paralisante e saída do próprio campo científico que está em disputa. Outro ponto

\footnotetext{
30 Há referências aos brasileiros Darcy Ribeiro, Milton Santos e Gustavo Lins Ribeiro. Ribeiro (2011) identificou essa ausência e desenvolveu a perspectiva "pós-imperialista" que incorpora a análise do Brasil.

${ }^{31}$ Para Calligaris, "escolher a viagem de Colombo como início da modernidade é, em suma, adotar uma metáfora que salienta alguns traços decisivos da subjetividade moderna" (Calligaris, 1999, p. 18).
} 
problemático é certa ausência de elaboração e preocupação com a teoria democrática no espectro da modernidade/colonialidade.

As grandes questões a serem colocadas para o grupo seriam: é possível romper com a lógica da colonialidade da modernidade sem que abandonemos as contribuições do pensamento ocidental/europeu/iluminista - especialmente, liberalismo e marxismo - para a própria decolonização ${ }^{32}$ ? Será que o êxito da sua proposta depende de sua própria condição subalterna e periférica? Qual o limite da implosão sobre a base epistemológica das ciências sociais? Será que, ao enfatizar superações e ao negar as influências do pós-estruturalismo, pós-marxismo e pós-colonialismo, o grupo não estaria criando uma nova hybris del punto cero? Como lidar com a paternidade europeia das nossas instituições e pensamentos políticos ${ }^{33}$ ? Como verificar empiricamente hoje o sujeito colonizado? Experiências consideradas decoloniais, como o novo constitucionalismo latino-americano andino, por exemplo, estariam então livres de contradições? Devem-se decolonizar as instituições políticas - ou quais seriam as instituições políticas decoloniais? Como operacionalizar metodologicamente a análise das escalas, níveis, esferas que a colonialidade perpassa? Os movimentos sociais atuais, em seus discursos e práticas, identificam a colonialidade e reivindicam a decolonização?

Essas perguntas mostram um campo promissor para agendas de pesquisa e discussões teóricas. Sem a pretensão de oferecer respostas definitivas, este artigo é um convite para que a ciência e a teoria política no Brasil considerem e dialoguem com o "giro decolonial" em curso na América Latina.

\section{Referências}

ALATAS, Syed Farid (2003). "Academic dependency and the global division of labour in the social sciences". Current Sociology, v. 51, n. 6, p. 599-613.

\footnotetext{
32 Aqui se faz referência não somente à democracia e aos direitos humanos, com toda a retórica imperialista e emancipatória que ao mesmo tempo assumem, como também a conceitos como: vida, felicidade, indivíduo, dignidade, liberdade, igualdade, responsabilidade etc.. Para uma visão interessantíssima da evolução desses ideais sob a evolução da formação dos estados e das formas do direito internacional cosmopolita, ver Brunkhorst (2011).

${ }_{33}$ Domingues responde essa questão da seguinte forma: "Nada do que é humano me é estranho, deveria ser nosso lema, pois o que emerge numa região de modo contingente num dado momento, e assim ocorreu com a modernidade, pode ser apropriado autenticamente por qualquer indivíduo ou coletividade, desde que responda as suas necessidade e expectativas concretas. O que importa é o que fazemos com ela. Evidentemente, isso tampouco quer dizer que a modernidade será a última estação da história, que permanece aberta para seus desenvolvimentos futuros"(Domingues, 2011, p. 13).
} 
ALMEIDA, Sandra (2010). "Prefácio", em SPIVAK, Gayatri. Pode o subalterno falar? Belo Horizonte: Editora da UFMG.

BRUNKHORST, Hauke (2011). "Alguns problemas conceituais do cosmopolitismo global". Revista Brasileira de Ciências Sociais, n. 76, p. 7-38.

CALLIGARIS, Contardo (1999). “A psicanálise e o sujeito colonial", em SOUSA, Edson (org.). Psicanálise e colonização. Porto Alegre: Artes e fícios. CASANOVA, Pablo González (2002). Exploração, colonialismo e luta pela democracia na América Latina. Rio de Janeiro: Vozes; Buenos Aires: Clacso.

CASTRO-GÓMEZ, Santiago (2005a). "Ciências sociais, violência epistêmica e o problema da 'invenção do outro", em LANDER, Edgardo (org.). A colonialidade do saber: eurocentrismo e ciências sociais, perspectivas latino-americanas. Buenos Aires: Clacso.

(2005b). La poscolonialidad explicada a los niños. Bogotá: Universidad del Cauca, Instituto Pensar.

(2005c). La hybris del punto cero: ciencia, raza e ilustración en la Nueva Granada (1750-1816). Bogotá: Editorial Pontificia Universidad Javeriana.

CASTRO-GÓMEZ, Santiago \& MENDIETA, Eduardo (1998). "Introducción: la translocalización discursiva de Latinoamérica en tiempos de la globalización", em CASTRO-GÓMEZ, Santiago \& MENDIETA, Eduardo (coords.). Teorías sin disciplina: latinoamericanismo, poscolonialidad y globalización en debate. México: Miguel Ángel Porrúa.

CASTRO-GÓMEZ, Santiago \& GROSFOGUEL, Ramon (2007). "Prólogo. Giro decolonial, teoría crítica y pensamiento heterárquico", em CASTRO-GÓMEZ, Santiago \& GROSFOGUEL, Ramon (coords.) El giro decolonial: reflexiones para uma diversidad epistêmica más allá del capitalismo global. Bogotá: Siglo del Hombre, Universidad Central, Instituto de Estudios Sociales Contemporáneos, Pontificia Universidad Javeriana, Instituto Pensar.

CONNELL, Raewyn (2007). Southern theory. Cambridge: Polity Press. (2012). CONNELL, Raewyn. "A iminente revolução na teoria social". Revista Brasileira de Ciências Sociais, n. 80, p. 9-20.

COSTA, Sérgio (2006). Dois Atlânticos: teoria social, anti-racismo e cosmopolitismo. Belo Horizonte: Editora UFMG. 
DOMINGUES, José Maurício (2011). Teoria crítica e semi(periferia). Belo Horiozonte: Editora UFMG.

DUSSEL, Enrique (2000). “Europa, modernidad y eurocentrismo”, em LANDER, Edgardo (coord.). La colonialidad del saber: eurocentrismo y ciencias sociales, perspectivas latino-americanas. Buenos Aires: Clacso.

ESCOBAR, Arthuro (2003). "Mundos y conocimientos de otro modo: el programa de investigación modernidad/colonialidad latinoamericano". Tabula Rasa, n. 1, p. 58-86.

FANON, Franz (2010). Os condenados da terra. Juiz de Fora: Editora UFJF. FERES Jr., João \& POGREBINSCHI, Thamy (2010). Teoria política contemporânea. Rio de Janeiro: Elsevier.

GROSFOGUEL, Ramón (2007). "Descolonizando los universalismos occidentales: el pluri-versalismo transmoderno decolonial desde Aimé Césaire hasta los zapatistas", em CASTRO-GÓMEZ, Santiago \& GROSFOGUEL, Ramon (coords.) El giro decolonial: reflexiones para uma diversidad epistêmica más allá del capitalismo global. Bogotá: Siglo del Hombre Editores, Universidad Central, Instituto de Estudios Sociales Contemporáneos, Pontificia Universidad Javeriana, Instituto Pensar. (2008). "Para descolonizar os estudos de economia política e os estudos pós-coloniais: transmodernidade, pensamento de fronteira e colonialidade global". Revista Crítica de Ciências Sociais, n. 80, p. 115-147. JONES, Branwen (ed.) (2006). Decolonizing international relations. Lanham: Rowman \& Littlefield.

LACLAU, Ernesto \& MOUFFE, Chantal (1985). Hegemony and socialist strategy: towards a radical democratic politics. Londres: Verso.

LANDER, Edgardo (2006). "A ciência neoliberal”, em CECEÑA, Esther (org.). Desafios das emancipações em um contexto militarizado. Buenos Aires: Clacso.

MALDONADO-TORRES, Nelson (2007). "Sobre la colonialidad del ser: contribuciones al desarrollo de un concepto”, em CASTRO-GÓMEZ, Santiago \& GROSFOGUEL, Ramon (coords.) El giro decolonial: reflexiones para uma diversidad epistêmica más allá del capitalismo global. Bogotá: Siglo del Hombre Editores; Universidad Central, Instituto de Estudios Sociales Contemporáneos, Pontificia Universidad Javeriana, Instituto Pensar.

GRUPO LATINOAMERICANO DE ESTUDIOS SUBALTERNOS (1998). 
"Manifiesto inaugural", em CASTRO-GÓMEZ, Santiago \& MENDIETA, Eduardo (orgs). Teorías sin disciplina: latinoamericanismo, poscolonialidad y globalización en debate. México: Miguel Ángel Porrúa.

MELMAN, Charles (2000). “O complexo de Colombo", em ASSOCIATION FREUDIENNE INTERNATIONALE (org.). Um inconsciente póscolonial, se é que ele existe. Porto Alegre: Artes e Ofícios.

MERLE, Marcel \& MESA, Roberto (1972). El anticolonialismo europeo. Madrid: Alianza.

MIGNOLO, Walter (1998). "Postoccidentalismo: el argumento desde América Latina”, em CASTRO-GÓMEZ, Santiago \& MENDIETA, Eduardo (coords.). Teorías sin disciplina: latinoamericanismo, poscolonialidad y globalización en debate. México: Miguel Ángel Porrúa.

(2002). "The geopolitics of knowledge and the colonial difference". The South Atlantic Quarterly, v. 101, n. 1, p. 57-95.

(2003). Historias locales/disenos globales: colonialidad, conocimientos subalternos y pensamiento fronterizo. Madrid: Akal.

(2007a). La idea de América Latina. La herida colonial y la opción decolonial. Barcelona: Gedisa.

(2007b). "El pensamiento decolonial: desprendimiento y apertura. Un manifiesto”, em CASTRO-GÓMEZ, Santiago \& GROSFOGUEL, Ramon (coords.). El giro decolonial: reflexiones para uma diversidad epistêmica más allá del capitalismo global. Bogotá: Siglo del Hombre Editores; Universidad Central, Instituto de Estudios Sociales Contemporáneos, Pontificia Universidad Javeriana, Instituto Pensar.

(2008). "La opción decolonial: desprendimiento y apertura. Um manifiesto y un caso". Tabula Rasa, n.8, p. 243-282.

(2010). Desobediencia epistémica: retórica de la modernidad, lógica de la colonialidad y gramática de la descolonialidad. Argentina: Ediciones del signo.

NAVAZ, Liliana \& CASTILO, Rosalva (coords.) (2008). Descolonizando el feminismo: Teorias y practicas desde los márgenes. Madri: Catedra.

QUIJANO, Aníbal (2000). "Colonialidad del poder y clasificación social”. Journal of world-systems research, v. 11, n. 2, p. 342-386.

(2005). Colonialidad y modernidad-racionalidad. Disponível em: $<$ http://pt.scribd.com/doc/36091067/Anibal-Quijano-Colonialidade-eModernidade-Racionalidade>. Acessado em 15 mar. 2013. 
QUIJANO, Aníbal \& WALLERSTEIN, Immanuel (1992). "Americanity as a concept, or the Americas in the modern world-system". International Social Science Journal, v. 44, n. 4, p. 549-557.

RIBEIRO, Gustavo Lins (2011). "Why (post)colonialism and (de)coloniality are not enough: a post-imperialist perspective”. Postcolonial Studies, v. 14 , n. 3, p. 285-297.

SANTOS, Boaventura Sousa (org.) (2005). Semear outras soluções: os caminhos da biodiversidade e dos conhecimentos rivais. Rio de Janeiro: Civilização Brasileira.

(org.) (2006). Conhecimento prudente para uma vida decente: um discurso sobre as ciências revisitado. São Paulo: Cortez.

SANTOS, Boaventura Sousa \& MENESES, Maria Paula (orgs.) (2010). Epistemologias do Sul. São Paulo: Cortez.

SUBRAHMANYAM, Sanjay (2004). “Prefácio”, em CHATTERJEE, Partha. Colonialismo, Modernidade e Política. Salvador: Edufba.

VISVANATHAN, Shiv (2004). "Convite para uma guerra da ciência”, em SANTOS, Boaventura Sousa (org.). Conhecimento prudente para uma vida decente: um discurso sobre as ciências revisitado. São Paulo: Cortez.

\section{Resumo}

O objetivo principal do artigo é o de apresentar a trajetória e o pensamento do Grupo Modernidade/Colonialidade (M/C), a partir de sua ruptura com os estudos subalternos -latino-americanos e indianos -, culturais e pós-coloniais, no final dos anos 1990 . O coletivo realizou um movimento epistemológico fundamental para a renovação crítica e utópica das ciências sociais na América Latina no século XXI: a radicalização do argumento pós-colonial no continente através da noção de "giro decolonial". O artigo está estruturado em duas partes. Em um primeiro momento, é traçada uma breve genealogia do pós-colonialismo. Posteriormente, apresenta-se a constituição do grupo $\mathrm{M} / \mathrm{C}$ e alguns conceitos centrais criados e compartilhados pelos seus principais expoentes. $\mathrm{O}$ trabalho pretende convidar o(a) leitor(a) para este debate, ainda incipiente na ciência e teoria Política no Brasil.

Palavras-chave: pós-colonialismo, estudos subalternos, Grupo Modernidade/Colonialidade, giro decolonial, América Latina.

\section{Abstract}

The aim of this article is to present the history and thought of the Modernity/Coloniality (M/C) Group, from its split away from subaltern - Latin Americans and Indians -, cultural 
and postcolonial studies in the late 90 s. The group made a crucial epistemological move for critical and utopian renewal of social sciences in Latin America in the 21st century: the radicalization of the post-colonial argument through the ideia of "decolonial turn." At first, we draw a brief genealogy of postcolonialism. Subsequently, we present the establishment of the $\mathrm{M} / \mathrm{C}$ group and some central concepts created and shared by its main exponents. The paper intends to invite the reader to this unfamiliar debate in social science and political theory in Brazil.

Keywords: post-colonialism, subaltern studies, Modernity/Coloniality Group, decolonial turn, Latin America.

Recebido em 3 de setembro de 2012.

Aprovado em 9 de março de 2013. 